\title{
Treatment satisfaction with insulin glargine in patients with diabetes mellitus in a university hospital clinic in Sweden
}

\author{
M Annersten Gershater, ${ }^{*}$ A Frid, J Apelqvist
}

\section{Introduction}

Who is medical treatment intended for - the patient or the healthcare system? In the process of developing a new drug, the need and value of the medication from the patient's perspective is only asked for via biomedical parameters used in clinical trial situations.

Any new medication that is to be marketed in Europe must undergo a process of approval through the European Agency for the Evaluation of Medicinal Products (EMEA), ${ }^{1}$ following which it is approved to be sold within the European Community. After registration at a national level (in Sweden) by the Medical Products Agency (MPA), ${ }^{2}$ which also provides recommendations for treatment at a group level, pricing is negotiated and decided by the Pharmaceutical Benefits Board. ${ }^{3}$

\section{Authors}

M Annersten Gershater, RN, MNSc,

Research Nurse

A Frid, MD, Phd, Registrar

J Apelqvist, MD, Phd, Registrar,

Associate Professor

Department of Endocrinology, Malmö University Hospital, Malmö, Sweden

*Correspondence to:

M Annersten Gershater, Department of Endocrinology, Malmö University Hospital Ing 51, SE 20502 Malmö, Sweden e-mail: magdalena.gershater@skane.se

Received: 21 July 2008

Accepted in revised form: 13 January 2009

\begin{abstract}
Background: Few studies evaluate patients' perspectives when a new drug is introduced to treat chronic diseases such as diabetes mellitus. The clinical role of a new insulin treatment, in terms of the relationship between higher cost and better treatment outcomes (as defined from the patient perspective) has been discussed. We sought to explore patient satisfaction with a new insulin treatment (insulin glargine). At its launch in 2002/3 it was purported to provide constant, peakless insulin release following once- or twice-daily administration, thus leading to fewer hypoglycaemic episodes while providing metabolic control equivalent to that achieved with NPH human basal insulin.

Aims: To investigate the indications used for prescription of a new drug and its clinical effects on glycosylated haemoglobin $\left(\mathrm{HbA}_{1 \mathrm{c}}\right)$ levels, perceived hypoglycaemic events and patient satisfaction.

Methods: The Diabetes Treatment Satisfaction Questionnaire (Status Version, DTSQ-s), which measures satisfaction with treatment regimen, and perceived frequency of hyperglycaemia and hypoglycemia, was circulated to all living patients who had ever started treatment with insulin glargine at the Department of Endocrinology at Malmö University Hospital. Medical records of 913 patients were assessed for $\mathrm{HbA}_{1 \mathrm{c}}$ levels at 0 and 12 months after starting insulin glargine therapy. Results: Completed questionnaires were returned by 615 of 960 patients (64\%) who had ever started insulin glargine. The main indications for starting treatment were physicians' or nurses' initiatives, desire for fewer fluctuations and improved metabolic control. $\mathrm{HbA}_{1 \mathrm{c}}$ levels fell by $0.41 \%$ for patients with type 1 diabetes and by $0.68 \%$ for those with type 2 diabetes. The mean DTSQ-s score was 28.45 for satisfaction, whereas the mean perceived hypoglycaemic/hyperglycaemic events score was 3 . Conclusion: Treatment satisfaction was very high and perceived frequency of hypoglycaemia/hyperglycaemia was very low. The indications for treatment of insulin glargine are being followed in accordance with national recommendations.
\end{abstract}

Eur Diabetes Nursing 2009; 6(1): 17-22

\section{Key words}

Diabetes treatment satisfaction; insulin glargine; patient perspective; hypoglycaemia; hyperglycaemia

This organisation also decides whether or not the product will be included in the reimbursement system. ${ }^{3}$ The National Board of Health and Welfare ${ }^{4}$ provides national guidelines on the treatment of certain diseases, and at a regional level, local pharmaceutical committees implement recommendations for treatment where specific brands are recommended for use, based on documentation and price. Pricing is without exception decided from the pharmaceutical industry and authorities' perspective about what is best for the patient. This is mainly a paternalistic approach that aims to keep control over drug expenses for the reimbursement authority. In Sweden, patient organisations are not involved in decision-making regarding drug recommendations and pricing.

A typical example of how the process works in practice was 
observed when the long-acting insulin analogue insulin glargine was launched in Sweden. In May 2005, the MPA recommended that Neutral Protamine Hagedorn (NPH) insulin should be the standard basal treatment for most insulin-treated patients, stating that there is no reason to switch from a well-functioning NPH treatment to insulin glargine or detemir, if the patient has no problems with hypoglycaemia. ${ }^{5}$ The MPA also advised that long-acting insulin analogues such as glargine or detemir should be reserved for the following candidates:

- Individuals with type 1 diabetes with either frequent nocturnal hypoglycaemia; or

- Individuals in whom the treatment goal for $\mathrm{HbA}_{1 \mathrm{c}}$ is not achieved because of recurring hypoglycaemia related to NPH insulin use; or

- Individuals with particular symptomatic fluctuations in plasma glucose levels. ${ }^{5}$

For type 2 diabetes patients, the MPA recommended that insulin glargine or detemir should be reserved for those with recurrent nocturnal hypoglycaemia or people who were not achieving treatment goals for $\mathrm{HbA}_{1 \mathrm{c}}$ because of recurrent hypoglycaemia related to NPH treatment. ${ }^{5}$

The MPA recommendations did not take into consideration patient influence in terms of choice or informed choice as described in the National Guidelines on the care and treatment of diabetes mellitus ${ }^{4}$ (which state that patients should be provided with tools to control their disease and how it affects their life), and in the Swedish Diabetes Association's Fundamental Principles ${ }^{6}$ (where the policy of interest describes the patient as a healthcare consumer who should have the opportunity to receive diabetes care that offers what the individual requires, in order to achieve the agreed treatment goals). Long-acting insulin analogues could be such a tool.

Insulin glargine was launched in 2002/2003, claiming to offer better outcomes with regard to stable slow release of insulin following a oncedaily injection, thus providing stable and predictive long-acting basal treatment and decreased frequency of hypoglycaemia compared with traditionally used NPH insulin. ${ }^{7}$ The price, conversely, was about twice as much as that for traditionally used NPH insulin. A systematic literature review, which assessed what advantages insulin glargine offered compared with NPH insulin, revealed that glargine and NPH insulin both reduced hyperglycaemia, that there was no difference in $\mathrm{HbA}_{1 \mathrm{c}}$ levels between the two treatments, and that hypoglycaemia assessment was not standardised in the included studies. ${ }^{8}$ Consequently, no conclusions could be made regarding any reduction of hypoglycaemia. ${ }^{8}$ Patient satisfaction or quality of life was not an issue. These findings prompted a discussion regarding the clinical role of insulin glargine, which centred on the following issues:

- If this treatment is more expensive and does not provide better outcomes compared with NPH, could it be defended?

- How is 'outcome of treatment' defined?

- What is the patient perspective regarding the new therapeutic option?

\section{Aims}

The present study sought to investigate the indications for prescribing a new drug (insulin glargine) and its clinical outcomes on $\mathrm{HbA}_{1 \mathrm{c}}$ levels, perceived hypoglycaemic events and patient satisfaction.

\section{Patients and methods}

The Department of Endocrinology at Malmö University Hospital provides care for most of the diabetes type 1 patients living in the town (which had 269142 inhabitants as of 1 January 2005) and type 2 diabetes patients referred by general practitioners. The department is also responsible for patients from the wider region who have diabetesrelated complications. The clinic was visited by 2289 diabetes patients $>18$ years old (with type 1 or type 2 diabetes) during 2004, of whom 360 underwent a 1-5-day problembased learning educational programme. ${ }^{9}$

The Diabetes Treatment Satisfaction Questionnaire (DTSQ) and a demographic questionnaire were mailed during spring 2005 to 960 patients' home addresses. ${ }^{10}$ These constituted all living patients who had at any time been prescribed insulin glargine by Malmö University Hospital, Clinic of Endocrinology (or any other clinic) until December 2004, as described in the electronic medical records.

An introductory letter explained the purpose of the study, assuring participants' anonymity and freewill participation. After three weeks a reminder was sent to all 960 patients. The DTSQ Status Version (DTSQ-s) was used in this survey. ${ }^{10}$ This instrument measures satisfaction with the treatment regimen (six items), perceived frequency of hyperglycaemia (one item) and perceived frequency of hypoglycaemia (one item) over the previous few weeks. The DTSQ has previously been translated from English to Swedish and validated, ${ }^{11}$ and is recommended by the World Health Organization (WHO), the International Diabetes Federation (IDF) ${ }^{12}$ and the Swedish Nurses' Association $^{13}$ for use in the quality assurance process for diabetes treatment programmes. 
The demographic questionnaire contained questions about age, sex, type of diabetes, diabetesrelated complications, duration of therapy and previous insulin treatment. The patient was also asked an open question about whether he/she wished to switch insulin glargine for another treatment, and the reasons for his/her response. In addition, the medical records of all patients who were ever prescribed insulin glargine from our clinic $(n=913)$ were reviewed, to assess $\mathrm{HbA}_{1 \mathrm{c}}$ levels at the time of starting insulin glargine treatment and after a period of 12 months, and to establish the reasons for stopping insulin glargine if this occurred.

\section{Ethics}

The Regional Ethic's Review Board in southern Sweden approved the study. Returning the questionnaire was accepted as patient consent to participate.

\section{Statistics}

The descriptive statistics used were percentage, range, mean and median when appropriate. As DTSQ-s scores do not show normal distribution, medians are presented. The computer programs Excel (version 2000) and SPSS (version 11.0) were used.

\section{Results}

Completed questionnaires were returned by 615 patients. Baseline information and details of previous basal insulin treatment are given in Table 1. The patients reported between 0 and 5 diabetes-related complications (Table 2). Indications for prescribing insulin glargine were (more than one answer possible):

- At the physician's/nurse's suggestion, $49.2 \%$

- Patient wished to experience less fluctuation in blood glucose, $45.6 \%$

\begin{tabular}{|l|l|}
\hline Parameter & Percentage \\
\hline Sex & \\
Male & 48.0 \\
Female & 52.0 \\
\hline Diabetes type & \\
Type 1 & 74.0 \\
Type 2 & 20.0 \\
Other/no response & 7.0 \\
\hline Previous basal & \\
insulin treatment & \\
NPH insulin & 62.0 \\
No response & 17.8 \\
No insulin & 10.3 \\
Mix insulin & 9.0 \\
Insulin pump & 0.5 \\
\hline
\end{tabular}

Table 1. Baseline information on patients who completed the Diabetes Treatment Satisfaction Questionnaire Status Version $(n=615,64 \%$ of those mailed)

- Patient wished to achieve better metabolic control, $32.1 \%$

- Patient wished to experience fewer hypoglycaemic events, $21.6 \%$

- Patient wished to take one injection instead of two, $14.7 \%$

- Other reasons, $14.7 \%$.

According to the medical records, at the time of the first insulin glargine prescription in patients with type 1 diabetes, mean $\mathrm{HbA}_{1 \mathrm{c}}$ values were $7.67 \%$; for patients with type 2 diabetes the mean value was $8.15 \%$. After 12 months' insulin glargine treatment, the mean $\mathrm{HbA}_{1 \mathrm{c}}$ levels were $7.26 \%$ for type 1 diabetes patients and $7.47 \%$ for those with type 2 diabetes. This represents a reduction of $0.41 \%$ in $\mathrm{HbA}_{1 \mathrm{c}}$ levels for patients with type 1, and $0.68 \%$ for patients with type 2 diabetes.

At 12 months, 81 patients out of $913(8.9 \%)$ had stopped using insulin glargine. The most common reasons for stoppage were: starting NPH insulin therapy $(\mathrm{n}=20)$; starting insulin pump $(\mathrm{n}=17)$; deceased $(\mathrm{n}=15)$; starting oral treatment $(n=10)$; starting with mix insulin $(n=9)$; starting insulin detemir $(n=7)$. At this time point, three patients were not receiving pharmacological treatment for their diabetes.

A total of $80 \%$ of the 615 patients responding to the survey did not wish to revert to their previous treatment. The reasons were described in the open-ended question, and were assessed using content analysis. The main reasons for continuation were:

- Experience of a more stable blood glucose level

- Fewer injections

- Fewer hypoglycaemic episodes

- Greater freedom

- Increased sense of security.

The main reason given by patients who wished to revert to previous insulin treatment $(6.5 \%)$ was that insulin glargine had not met their expectations of achieving more stable blood glucose levels. The non-response rate for this question was $13.5 \%$.

\section{DTSQ-s results}

The questionnaire is presented in two parts: 'satisfaction with treatment'(6-36 points), where higher scores indicate greater rates of satisfaction, and 'perceived hyperand hypoglycaemia' (2-12 points), where lower scores indicate blood glucose levels closer to the ideal and higher scores indicate problems.

The scores are listed in Table 3. Forty-eight patients $(7.8 \%)$ scored the maximum of 36 for the treatment satisfaction section. The maximum rating score (6 points) was reported by:

- $23 \%$ of patients for the question, 'How satisfied are you with your current treatment?'

- $23.9 \%$ of patients for the question, 'How convenient have you been finding your treatment to be recently?' 
- $26.1 \%$ of patients for the question, 'How flexible have you been finding your treatment recently?'

- $28.7 \%$ of patients for the question, 'How satisfied are you with your understanding of your diabetes?'

- $45 \%$ of patients for the question, 'Would you recommend this form of treatment to someone else with your kind of diabetes?'

- $39.5 \%$ of patients for the question, 'How satisfied would you be to continue with your present form of treatment?'

The median score for all included items was 5. Differences in scoring as determined by gender were not statistically significant.

Patients reported the following rates of complications: no complications, five patients; one complication, two patients; two complications, one patient; three complications, two patients; four complications, one patient. Greater patient satisfaction was reported with increasing age, with the exception of the 12 patients aged $>80$ years. There was no difference in overall satisfaction between groups of patients with one or more self-reported diabetes complications. The 12 least-satisfied patients (scoring 6-12 points) did not differ regarding type of diabetes, gender, age or complication rate.

Perceived frequency of hyperglycaemia or hypoglycaemia each scored a median of 3 points. There was no significant difference between type of diabetes, gender, age or complication rate, in terms of perceived frequencies of these events.

\section{Discussion}

The majority of patients experienced more stable blood glucose levels, which revealed that the suggestion of treatment change was appropriate and was in line

\begin{tabular}{|c|c|c|c|}
\hline & $\begin{array}{l}\text { Type } 1 \text { diabetes } \\
n=445\end{array}$ & $\begin{array}{l}\text { Type } 2 \text { diabetes } \\
n=118\end{array}$ & $\begin{array}{l}\text { All diabetes types } \\
\text { (including 'others') } \\
n=599\end{array}$ \\
\hline & n $\quad(\%)$ & n $(\%)$ & n $\quad(\%)$ \\
\hline Hypertension & $141(31.7)$ & 68 (57.6) & $220(36.7)$ \\
\hline Dyslipidaemia & 107 (24.0) & $44(37.2)$ & $160(26.7)$ \\
\hline Retinopathy & $76 \quad(17.1)$ & 18 (15.3) & $96 \quad(16.0)$ \\
\hline Heart disease & 52 (11.7) & 29 (24.6) & (14.5) \\
\hline Nephropathy & 39 (8.8) & $14(11.9)$ & $(9.2)$ \\
\hline Foot ulcer & 31 (7.0) & 14 (11.9) & $(7.7)$ \\
\hline Neuropathy & 37 (8.3) & 9 (7.6) & $46 \quad(7.7)$ \\
\hline
\end{tabular}

Table 2. Self-reported diabetes complications by patients responding to a questionnaire about insulin glargine use (not all respondents answered the question)

\begin{tabular}{|l|l|l|l|}
\hline $\begin{array}{l}\text { Item (median scores for each item; } \\
\mathbf{1}=\text { not at all, } \mathbf{6}=\text { most of the time) }\end{array}$ & $\begin{array}{l}\text { Type 1 } \\
\mathbf{n}=\mathbf{4 5 3}\end{array}$ & $\begin{array}{l}\text { Type 2 } \\
\mathbf{n}=\mathbf{1 2 1}\end{array}$ & $\begin{array}{l}\text { All (including } \\
\text { 'other') } \mathbf{n = 6 1 5}\end{array}$ \\
\hline Satisfaction with treatment: & 5.00 & 5.00 & 5.00 \\
Satisfaction & 5.00 & 5.00 & 5.00 \\
Convenience & 5.00 & 5.00 & 5.00 \\
Flexibility & 5.00 & 5.00 & 5.00 \\
Understanding & 5.00 & 5.00 & 5.00 \\
Recommend to others & 5.00 & 5.00 & 5.00 \\
Wish to continue & $\mathbf{2 8 . 5 4}$ & $\mathbf{3 0 . 6 2}$ & $\mathbf{2 8 . 4 5}$ \\
\hline Mean treatment satisfaction total & & & \\
score (out of a maximum total \\
score of 36 points)
\end{tabular}

Table 3. Diabetes Treatment Satisfaction Questionnaire (Status Version) scores obtained from patients receiving insulin glargine

with MPA recommendations and National Guidelines. ${ }^{4,5}$

A reduction in $\mathrm{HbA}_{1 \mathrm{c}}$ levels with insulin glargine $(0.41 \%$ units, type 1 diabetes; $0.68 \%$ units, type 2 diabetes), with a low degree of perceived hypoglycaemic events, is expected, taking into account the heterogeneity of a complex patient group that includes patients with diabetic complications, from all social strata. Perceived frequency of hyperglycaemia scored 3.07 on the DTSQ-s for all patients, which is higher than the 2.8 score included in a study by Witthaus et al. ${ }^{14}$ Part of this scoring difference could be explained by the broad inclusion criteria. There was no difference in the scores between males and females. The hypoglycaemia score of 2.57 that we report for all 
patients (2.68 for type 1 diabetes; 2.21 for type 2 diabetes) is equivalent to the previous study. ${ }^{14}$

The present study revealed that $75 \%$ of the participants were satisfied with insulin glargine treatment; only $6.5 \%$ would prefer to change to another treatment. It is important that the physician responsible for treatment recognises such patients and prescribes a more suitable treatment according to individual needs. For those who did not wish to change treatment, it is important that their opinion is taken seriously according to National $^{4}$ and Swedish Diabetes Association $^{6}$ guidelines, and that access to preferred treatment is also enabled in the future.

A study using the DTSQ conducted by Hirsch et al, involving 144 type 2 diabetes patients (commencing different diabetes treatments) and patient education revealed no differences between those who had more than one diabetes complication after four weeks' intervention. ${ }^{15}$ This concurs with our findings. Comparison with other studies is difficult as most previous studies using the DTSQ are randomised controlled trials (RCT) that have excluded patients with severe complications. Our score has been collected from patients in everyday clinical situations and our questionnaire produced a relatively high response rate. The present study findings did not reveal any relationship between total score and comorbidity. The high scores obtained for the item about understanding the disease is interpreted as a good reference to the educational programme offered at the clinic. DTSQ-s scores from the present study are comparable with the findings of Ashwell et $a l,{ }^{16}$ despite the fact that their study only included patients with type 1 diabetes.

We believe that patients who have a high degree of treatment satisfaction, a low degree of hypoglycaemia and a low degree of hyperglycaemia are prone to consume less healthcare resources and experience fewer hospitalisations.

We consider our response rate of $64 \%$ to be good, taking into account that questionnaires were mailed to all living patients who had ever started treatment with insulin glargine at Malmö University, with no exceptions. Seven questionnaires were returned from the post office, marked 'address unknown'. The patients' general health is not as good as in an RCT setting, but in this way a truer picture is revealed. A relatively small proportion of the patients state that they have type 2 diabetes, which reflects the university hospital clinic situation. In general, patients with type 2 diabetes who are treated at university hospitals suffer from more diseases and more complications compared with other people with type 2 diabetes.

As the questionnaire was anonymous, analysis cannot be performed on non-respondents. Theoretically, this group might consist of even more severely ill patients. Insulin detemir use was not investigated as the number of patients on this insulin was too small at the time of the survey. In absence of standardised criteria for the assessment of hypoglycaemic events, we consider patients' subjective experiences as being valuable. One of the targets for using the DTSQ is as a routine part of clinical audit cycles, ${ }^{9}$ which is how we use the instrument. Hirsch et $a l^{15}$ described general well-being and specific treatment satisfaction to be different quality-of-life (QoL) dimensions. We do not consider the DTSQ to be a QoL instrument; it is merely a useful tool for evaluating the quality of diabetes care given at a clinic. Measurements of patient satisfaction with regard to a certain treatment or programme are important complements to biomedical parameters when RCTs are conducted. Subsequent follow-up in an everyday clinical setting provides the foundation for developing treatment guidelines and improving diabetes care, which have to be perpetual processes. Asking the patients' opinions might enable patients to become more involved in their care, and might lead to better collaboration between diabetes team members and patients, and more holistic care. If patients are satisfied with treatment, in this case with a new insulin, and consider it to be meaningful, the possibilities of a positive outcome ( $\mathrm{g}$ reduction in blood glucose level, reduced risk of hypoglycaemia and maintained or improved QoL) increase.

In conclusion, this study demonstrated that patients were satisfied with insulin glargine treatment, as measured with the DTSQ-s, and the majority of patients did not wish to change treatment. $\mathrm{HbA}_{1 \mathrm{c}}$ levels were slightly improved.

\section{Conflict of interest statement:}

Magdalena Annersten Gershater is a member of the Bayer Advisory Board; and Anders Frid has received honoraria for lectures from sanofi-aventis.

\section{References}

1. European Agency for the Evaluation of Medicinal Products. http:// www.emea.europa.eu [Accessed 16 January 2009].

2. Medical Products Agency. http:/ /www.lakemedelsverket.se/Tpl /StartPage__395.aspx [Accessed 16 January 2009].

3. Pharmaceutical Benefits Board. http://www.lakemedelsformansnam nden.se/in-english/reimbursementreview/ [Accessed 26 January 2009].

4. Swedish National Board of Health and Welfare. http://www.social styrelsen.se/en/ [Accessed 16 January 2009].

5. Medical Products Agency. Behand- 
lingsrekommendation Användning av långverkande insulinanaloger. Information från Läkemedelsverket Årgång 16; 2005.

6. Fundamental Principles of Swedish Diabetes Association. http://www.dia betes.se [Accessed 3 February 2009].

7. Lepore M, Pampanelli S, Fanelli C, et al. Pharmacokinetics and pharmacodynamics of subcutaneous injection of long-acting human insulin analog glargine, NPH insulin, and ultralente human insulin and continuous subcutaneous infusion of insulin lispro. Diabetes 2000; 49: 2142-2148.

8. Björk Linné A, Liedholm $\mathrm{H}$ Insulinglargin- en systematisk översikt av behandlingsstudier. Inga dokumenterade fördelar med Lantus ${ }^{\circledR}$ jämfört med NPH-insulin. Läkartidningen 2004; 101: 2002-2007.

9. Wetterholtz I , Lundberg M, Berntorp $\mathrm{K}$, et al. Process of Change in Diabetes Education Day-care in Malmö,
Sweden. Abstract and Poster presentation at the 10th FEND Conference, Athens, Greece, September 2005. P12.

10. Bradley C, The Diabetes Treatment Satisfaction Questionnaire: DTSQ. In: Handbook of psychology and diabetes: a guide to psychological measurement in diabetes research and practice. Bradley C (ed). Chur: Harwood Academic Publishers, 1994.

11. Wredling R, Stålhammar J, Adamson $\mathrm{U}$, et al. Wellbeing and treatment satisfaction in adults with diabetes: a Swedish population based study. Qual Life Res 1995; 4: 515-522.

12. Bradley C, Gamsu DS for the psychological well-being working group of the WHO/IDF St Vincent Declaration Action Program for Diabetes. Guidelines for encouraging psychological well-being: Report of a working group of the World Health Organization Regional Office for Europe and International Diabetes Federation European
Region St Vincent Declaration Action Program for Diabetes. Diabet Med 1994; 11: 510-516.

13. Swedish Nurses' Association and Gotha: Quality Indicators in Nursing. Stockholm: Gotha, 2001.

14. Witthaus E, Stewart J, Bradley C. Treatment satisfaction and psychological well-being with insulin glargine compared with $\mathrm{NPH}$ in patients with type 1 diabetes. Diabet Med 2001; 18: 619-625.

15. Hirsch A, Bartholomae C, Volmer T. Dimensions of quality of life in people with non-insulin-dependent diabetes. Qual Life Res 2000; 9: 207-218.

16. Ashwell SG, Bradley C, Stephens JW, et al. Treatment satisfaction and quality of life with insulin glargine plus insulin lispro compared with NPH insulin plus unmodified human insulin in individuals with type 1 diabetes. Diabetes Care 2008; 6: 1112-1117.

\section{European Diabetes Nursing}

\section{Cinhal $*$ PsyclNFO $*$ EMBASE $*$ SCOPUS}

\section{Original research $\star$ Conference notes}

\section{Review papers ${ }^{*}$ Case studies}

\section{Short reports ${ }_{\star}$ Comments}

\section{Online at Wiley Interscience}

The Co-Editors welcome contributions to the journal of all types, whether original research, reviews, case reports, conference reports, comments etc.

If you would like to contribute to the journal please contact the Editorial Office for a copy of the Guidelines for Authors, or see page 39 of this issue.

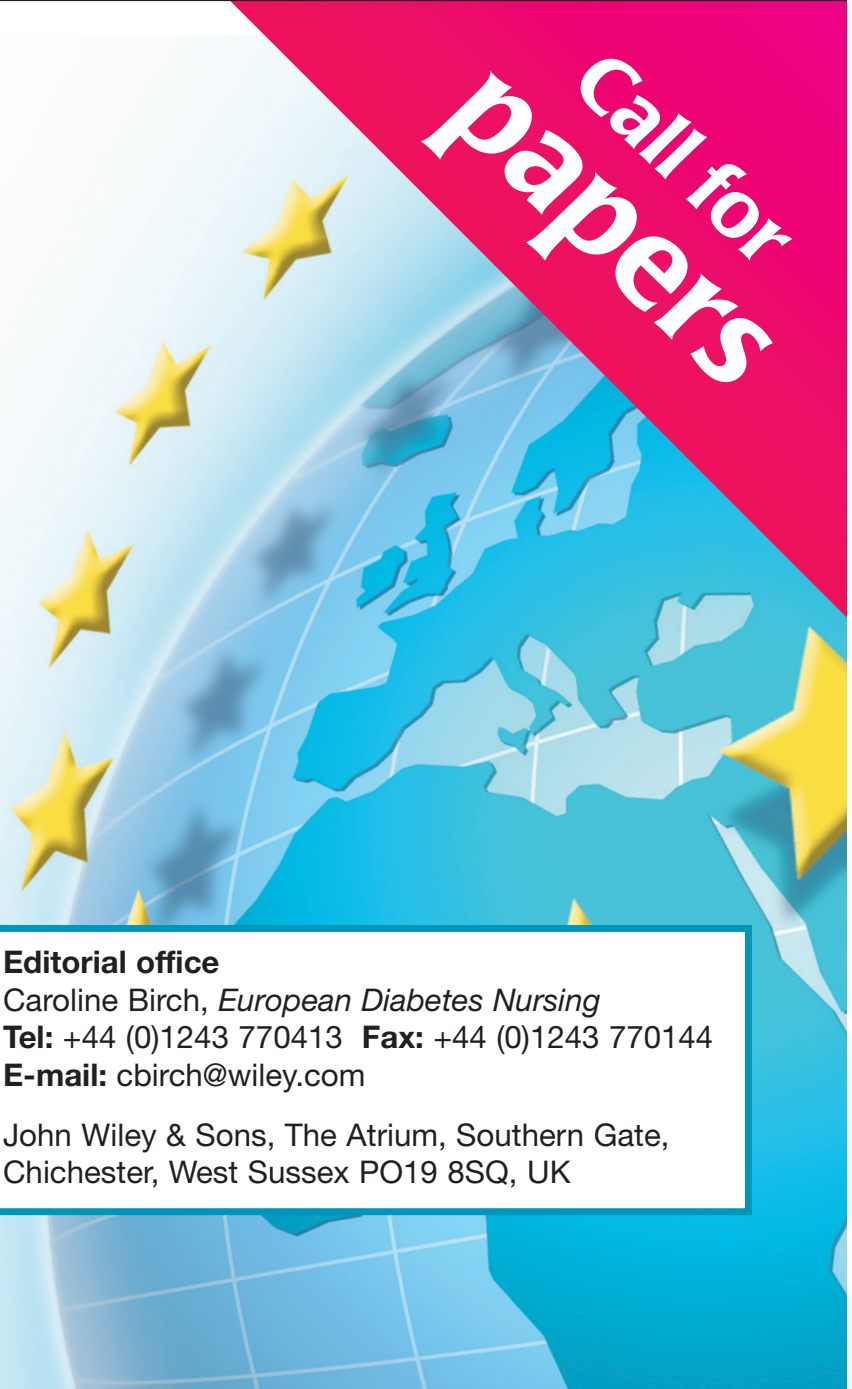

